\title{
Infection of female squirrel monkeys (Saimiri sciureus) with Trichomonas vaginalis as a model of trichomoniasis in women
}

\author{
D A STREET*, D TAYLOR-ROBINSON*, AND C M HETHERINGTON† \\ From the *Sexually Transmitted Diseases Research Group, Division of Communicable Diseases, Clinical \\ Research Centre, Harrow, Middlesex; and the †Animal Division, National Institute for Medical Research, \\ London
}

SUMMARY Marmosets, tamarins, owl monkeys, and squirrel monkeys were inoculated intravaginally with Trichomonas vaginalis. The latter animal species was most susceptible, trichomonads being recovered from four of six monkeys for periods ranging usually up to one month. Vaginal discharge was seen in most infected animals but polymorphonuclear leucocytes were rare. Infected animals developed serum IgG antibody responses and also local IgG and IgA responses, the latter occurring sometimes on reinoculation in the absence of organism recovery. Antibody responses were, however, of short duration and, overall, immunity was weak because two animals were reinfected on a second or subsequent challenge. Some of the observations are relevant to vaginal trichomoniasis in women.

\section{Introduction}

One of the difficulties encountered in studying the pathogenicity of Trichomonas vaginalis is the lack of a suitable animal model which reflects trichomoniasis of the human genital tract. Numerous attempts have been made to infect a variety of animals and these have been summarised by Trussell ${ }^{1}$ and Honigberg. ${ }^{2}$ A number of routes of inoculation were used but intravaginal inoculation apparently met with limited success. Only a few of the attempts involved the use of non-human primates ${ }^{3-5}$ and all of these were rhesus monkeys (Macaca mulatta). The proportion of animals becoming infected was different in each study, but at least some asymptomatic infections were recorded. This suggested that in searching for a convenient model further exploration of non-human primates would be worthwhile. We therefore inoculated the lower genital tract of four species of female monkey with $T$ vaginalis and found that two of them were susceptible. Further cultural and serological studies indicate that infection of female squirrel monkeys is similar in several respects to trichomoniasis of the genital tract in women.

Address for reprints: Dr D Taylor-Robinson, Division of Communicable Diseases, Clinical Research Centre, Watford Road, Harrow, Middlesex HA1 3UJ

Accepted for publication 11 January 1983

\section{Materials and methods}

NON-HUMAN PRIMATES

Six marmosets (Callithrix jacchus), two tamarins (Saguinus labiatus), two owl monkeys (Aotus trivirgatus), and six squirrel monkeys (Saimiri sciureus) were used. All were female animals but the stage of the oestrus cycle and their ages were not known. They were housed in pairs in cages at the National Institute for Medical Research, Mill Hill, London, and were given food and water in unlimited quantities.

\section{TRICHOMONAS VAGINALIS}

Isolate 68471 was obtained from a woman who attended the Praed Street Clinic, St Mary's Hospital, London, with a green frothy vaginal discharge of two months' duration. A diagnosis of trichomoniasis was made from microscopical examination of a wet preparation of the discharge. This was confirmed by culturing $T$ vaginalis in Diamond's TYM medium ${ }^{6}$ without agar, supplemented with penicillin G $(500$ units $/ \mathrm{ml})$, streptomycin $(500 \mu \mathrm{g} / \mathrm{ml})$, and nystatin $(50 \mu \mathrm{g} / \mathrm{ml})$ to inhibit the growth of other microorganisms. The trichomonads were subcultured in the same medium and a final passage was made in Diamond's medium with agar but without antibiotics. The organisms were incubated at $37^{\circ} \mathrm{C}$ for 72 hours, at which time they were active and in 
the logarithmic phase of growth. No contaminating bacteria were found in the culture by subculturing to blood-agar medium and incubating aerobically and anaerobically. The trichomonads were harvested by centrifugation at $1000 \times g$ for five minutes and the number of motile trichomonads in the gelatinous pellet was estimated in a haemocytometer. These organisms were used to inoculate the animals.

\section{INOCULATION PROCEDURES}

A few animals were anaesthetised by intramuscular injection of alphaxalone (Saffan; Glaxo) $12 \mathrm{mg} / \mathrm{kg}$ body weight. Usually, however, marmosets and squirrel monkeys were not anaesthetised but inoculated while being restrained in a supporting device. The inoculum, prepared as described previously, was introduced into the vagina through a sterile cat catheter cut to approximately $15 \mathrm{~cm}$. Each marmoset and tamarin received $0.3 \mathrm{ml}$ of the inoculum containing $3 \times 10^{5}$ motile trichomonads. The larger owl and squirrel monkeys received $0.5 \mathrm{ml}-$ The larger owl and squirrel monkeys received $0.5 \mathrm{ml}$-that is, about $5 \times 10^{5}$ trichomonads. After inoculum was placed in $5 \mathrm{ml}$ of Squires' medium ${ }^{7}$ and incubated at $37^{\circ} \mathrm{C}$ to check the viability of the organisms.

In one experiment $T$ vaginalis organisms, isolated in Diamond's medium from one of the squirrel monkeys, were allowed to multiply for 48 hours. Then they were concentrated to about $10^{7}$ motile organisms per $\mathrm{ml}$ by centrifugation and $0.5 \mathrm{ml}$ introduced into the vagina of unanaesthetised squirrel monkeys. A gelatine sponge measuring $0.3 \times 1.0 \mathrm{~cm}$ was inserted in the vagina at the same time as the inoculum to help to prevent its leakage.

Two squirrel monkeys serving as controls received $0.5 \mathrm{ml}$ of Diamond's medium alone by intravaginal inoculation.

\section{SAMPLING AND CULTURE PROCEDURES Culture and identification of $T$ vaginalis}

Vaginal secretions were collected at least three times before inoculation of the monkeys with $T$ vaginalis and at intervals thereafter by means of sterile calcium-alginate swabs (Calgiswab type 1; Inolex, Glenwood, Illinois, USA). Each swab was agitated in $5 \mathrm{ml}$ of Squires' medium in a bijou at room temperature. The bijoux were either transferred directly to the laboratory at the Clinical Research Centre, there being an interval of two hours at room temperature, or incubated at $37^{\circ} \mathrm{C}$ for two days before being transferred. All cultures were incubated at $37^{\circ} \mathrm{C}$ for up to two weeks and were examined each day for motile trichomonads by transmitted-light micro- scopy ( $\times 100$ magnification). When protozoans were $\stackrel{\overparen{Q}}{\stackrel{\mathrm{C}}{-}}$ seen, which occurred usually within two days, they므. were examined more carefully by dark field microscopy ( $\times 100-400$ magnification) and by indirect immunofluorescence to confirm their identity as $T$ vaginalis.

\section{Bacteriological tests}

Vaginal specimens taken with calcium-alginate swabs were examined by conventional bacteriological culture procedures.

\section{Vaginal $\mathrm{pH}$ values}

The $\mathrm{pH}$ of the vaginal secretions of some squirrel monkeys before inoculation was assessed by using pH indicator paper (ROTA 4·5-7·5; May and Baker Ltd).

Assessment of inflammatory cell response

Vaginal material was collected using a calcium alginate swab, spread on a clean glass slide, and allowed to dry. The smear was fixed in methanol for $\stackrel{5}{\rightarrow}$ 20 minutes and stained with Giemsa's stain before being examined microscopically.

\section{Glycogen in vaginal cells}

Dried smears of vaginal material were occasionally stained with periodic acid Schiff (PAS) stain to assess the glycogen content of the epithelial cells.

\section{Serum samples for antibody tests}

An approximate $2 \mathrm{ml}$ volume of blood was removed from the femoral vein of each squirrel monkey? before vaginal inoculation and at intervals thereafter. The sera were separated and stored at $-70^{\circ} \mathrm{C}$.

\section{Vaginal secretions for antibody}

These were collected by insertion of a sponge (Weckcel surgical sponge; Edward Weck Co Ltd, South 을 Carolina, USA), measuring approximately $0.2 \times 0.5 \mathrm{~cm}$, into the vagina. The sponges were stored at $-70^{\circ} \mathrm{C}$ before the contents were expressed $N$ into $150 \mu \mathrm{l}$ of phosphate-buffered saline containing $4 \%$ bovine serum albumin and $0.01 \%$ Tween 20 . This solution was tested for antibody.

\section{ANTIBODY STUDIES}

Sera were tested for IgG antibody to $T$ vaginalis $\cong$ using an enzyme linked immunosorbent assay (ELISA) which had been used previously to detect 0 antibody to $T$ vaginalis in the sera of women. $8 \overrightarrow{\mathbb{D}}$ Vaginal secretions were tested for IgA and IgG antibodies to $T$ vaginalis by the same procedure. 


\section{Results}

INOCULATION OF MARMOSETS, TAMARINS, AND OWL MONKEYS

Six marmosets and two tamarins were inoculated intravaginally with $T$ vaginalis, but it was not recovered from any of the animals despite seven attempts at isolation from each of them over a period of 17 days. $T$ vaginalis was isolated from one owl monkey only on day 6 after inoculation, but it was never recovered from the other owl monkey despite nine attempts at recovery over 36 days.

\section{INOCULATION OF SQUIRREL MONKEYS}

In contrast to the almost complete failure to recover $T$ vaginalis from the monkeys mentioned previously, trichomonads were isolated from four of six squirrel monkeys and the results for individual animals are given in table I and below.

\section{Monkey $A$}

Isolation of $T$ vaginalis-It was isolated on days 1 , $3,6,10,13,20$, and 34 after inoculation. This was followed by seven negative culture attempts and the monkey was reinoculated 77 days after the first inoculation. Trichomonad-positive cultures were not obtained until 12 days after inoculation and required incubation at $37^{\circ} \mathrm{C}$ for 10 days before motile organisms were seen. They were recovered, however, for up to 28 days after this inoculation. The animal was inoculated for a third time, 126 days after its second inoculation, but 10 isolation attempts over 12 weeks were negative. The monkey was then caged with one male and five female culture-negative squirrel monkeys and $T$ vaginalis was isolated five weeks later. This was followed by seven negative isolation attempts over nine days but trichomonads were isolated on three occasions four weeks later after sterile medium had been introduced into the vagina.
Vaginal discharge-This was noticed one month after inoculation. It continued up to and after the second inoculation and became more pronounced and persisted after the third.

Antibody response-A serum IgG antibody titre of $1 / 128$, recorded one month after inoculation, diminished to $1 / 32$ seven days before the second inoculation. A titre of 1/512 was recorded 82 days after this. The titre had diminished to $1 /<844$ days thereafter, at the time of the third inoculation, and did not increase subsequently. However, both secretory IgA and IgG antibodies, not previously sought, increased in titre from $1 /<25$ to $1 / 1600$ two weeks after the third inoculation and had diminished to their original values after 12 weeks.

\section{Monkey $B$}

Isolation of $T$ vaginalis-It was isolated on days 12,28 , and 51 after inoculation. This was followed by three negative culture attempts and the monkey was reinoculated 126 days after the first inoculation. Trichomonads were then recovered on seven occasions over 28 days. Ten negative culture attempts were followed by a third inoculation 24 weeks after the second. Six isolation attempts over three weeks, however, failed to recover $T$ vaginalis.

Vaginal discharge-This was observed only after the second inoculation during which time $T$ vaginalis was recovered most frequently. The discharge continued for 19 weeks and did not recur after the third inoculation.

Antibody response-No serum IgG antibody response was detected after the first inoculation but four weeks after the second inoculation the serum IgG titre increased from $1 /<8$ to $1 / 1024$. Furthermore, the titre of secretory IgG increased from $1 /<25$ to $1 / 800$ and the titre of secretory $\operatorname{IgA}$ increased from $1 /<25$ to $1 / 400$. Eight weeks later, however, the titres of both serum and secretory antibodies had diminished to their original values.

TABLE I Observations on six squirrel monkeys inoculated intravaginally with $T$ vaginalis

\begin{tabular}{|c|c|c|c|c|c|c|c|c|}
\hline \multirow[b]{3}{*}{ Monkey } & \multirow{2}{*}{\multicolumn{4}{|c|}{$\begin{array}{l}\text { Duration (days) of infection } \\
\text { after indicated inoculation }\end{array}$}} & \multirow{3}{*}{$\begin{array}{l}\text { Vaginal } \\
\text { discharge* }\end{array}$} & \multicolumn{3}{|c|}{ Antibody response* } \\
\hline & & & & & & \multirow{2}{*}{$\begin{array}{l}\text { Serum } \\
\text { IgG }\end{array}$} & \multicolumn{2}{|l|}{ Local } \\
\hline & First & Second & Third & Fourth & & & $\operatorname{Ig} G$ & $\operatorname{Ig} A$ \\
\hline $\mathbf{A}$ & 34 & 28 & $(+)+$ & NA & ++ & + & $(+) \neq$ & $(+)$ \\
\hline B & 51 & 28 & - & NA & ++ & + & + & + \\
\hline C & 20 & - & - & - & \pm & + & $(+)$ & $(+)$ \\
\hline D & $(+) \S$ & NA & NA & NA & + & + & NT & NT \\
\hline$\overline{\mathbf{E}}$ & - & - & - & NA & \pm & - & $(+)$ & $(+)$ \\
\hline$\overline{\mathbf{F}}$ & - & - & NA & NA & \pm & - & - & - \\
\hline
\end{tabular}

*See text for details. NA = not attempted NT = not tested

tRecovery of trichomonads after caging with other monkeys and also after installation of medium (see text)

$\$(+)$ Antibody responses not associated with recovery of trichomonads

§Recovery of trichomonads after caging with other monkeys (see text) 


\section{Monkey $C$}

Isolation of $T$ vaginalis-It was isolated only on days 6 and 20 after inoculation, 10 attempts to isolate the trichomonads thereafter over a period of seven weeks being unsuccessful. Reinoculations 11, 29, and 57 weeks after the first inoculation did not result in further infections, as gauged by 32 unsuccessful attempts to recover the organisms.

Vaginal discharge-A slight discharge occurred for about one week after the third inoculation but not before or after.

Antibody response-A serum IgG antibody titre of $1 / 1024$ was recorded five weeks after the first inoculation. This titre was not maintained after the reinoculations and had diminished to 1/64 23 weeks after the first inoculation and to $1 /<8$ after 33 weeks. Secretory antibody was not sought until the third inoculation. Thereafter, over a period of two weeks, the secretory IgG and IgA titres increased from $1 /<25$ to $1 / 800$ and $1 / 100$ respectively but had diminished to their original values after 12 weeks.

\section{Monkey $D$}

Isolation of $T$ vaginalis-After inoculation eight attempts to recover $T$ vaginalis during four weeks failed. However, seven and 13 weeks after caging with one male and five female culture-negative squirrel monkeys, mentioned previously with regard to monkey $A$, trichomonads were isolated from the vagina. They were not recovered thereafter, depite 12 isolation attempts, nor after instillation of medium into the vagina 20 weeks after caging with the other monkeys.

Vaginal discharge-This was noted at the same time as the first recovery of $T$ vaginalis. It persisted for one week and was not detected before or after.

Antibody response-The serum IgG antibody titre increased from $1 /<8$ to $1 / 128$ at the time of the first recovery of $T$ vaginalis; six and nine weeks later the titres were $1 / 512$ and $1 / 64$ respectively.

\section{Monkey $E$}

This monkey was inoculated on three occasions, at intervals of 18 and 24 weeks, but $T$ vaginalis was not recovered despite 32 isolation attempts. A slight discharge, which lasted for about seven days, was noted after the second inoculation. Serum IgG antibody was not detected at any time. Secretory IgG and IgA antibody titres, however, increased from $1 /<25$ to $1 / 400$ and $1 / 800$ respectively two weeks after the second inoculation and diminished to their original values 10 weeks later.

\section{Monkey $F$}

This monkey was inoculated on two occasions, 23 weeks apart, but $T$ vaginalis was not recovered despite 23 isolation attempts. Three days after the $\stackrel{\overparen{\mathbb{Q}}}{-}$ second inoculation, however, it developed a 드. discharge which persisted for two weeks. Neither serum IgG nor secretory IgG or IgA antibodies were detected at any time.

\section{Monkeys serving as controls}

$T$ vaginalis was not isolated from two squirrel monkeys inoculated intravaginally with Diamond's medium only. Furthermore, they did not develop a vaginal discharge nor antibody responses.

\section{OTHER FEATURES}

None of the monkeys inoculated with $T$ vaginalis appeared clinically ill. Examination of Giemsastained vaginal smears indicated that despite an occasional discharge there was no polymorphonuclear leucocyte response in any of the animals. PAS-stained smears failed to show any difference between the glycogen content of the epithelial cells of those monkeys which became infected and those which did not. The vaginal $\mathrm{pH}$ of all monkeys before inoculation was about $6 \cdot 5-7 \cdot 0$, as was the $\mathrm{pH}$ of inoculated but uninfected animals. Only monkey D was tested when culture-positive, and the vaginal $\mathrm{pH}$ was found to be $<6.5$. Examination of the vaginal bacterial flora of four of the monkeys (table II) showed that there was little difference between the flora of the monkey which was infected (B) at the time of examination and those which were not $(A, C$, and $E)$. In contrast to the flora of the normal human vagina, lactobacilli were never isolated.

TABLE II Bacteria isolated from vaginal secretions of four squirrel monkeys $(A, B, C$, and $E)$

\begin{tabular}{|c|c|c|c|c|}
\hline Bacteria isolated & $\begin{array}{l}A \\
\text { (None*) }\end{array}$ & $\begin{array}{l}\text { B } \\
\text { (Slight*) }\end{array}$ & $\begin{array}{l}\text { C } \\
\text { (None*) }\end{array}$ & $\begin{array}{l}E \\
\text { (Moderate }\end{array}$ \\
\hline $\begin{array}{l}\text { Enterococci } \\
\text { Staphylococcus }\end{array}$ & + & - & + & - \\
\hline epidermidis & + & - & - & - \\
\hline Proteus spp & \pm & - & \pm & + \\
\hline Eubacterium spp & ++ & $+t+$ & ++ & $+t+$ \\
\hline $\begin{array}{l}\text { Pasteurella intermedius } \\
\text { Pasteurella anaerobius }\end{array}$ & $\begin{array}{l} \pm \\
\pm\end{array}$ & $\begin{array}{l}+t \\
-\end{array}$ & $\begin{array}{l}++ \\
-\end{array}$ & $\begin{array}{l}+++ \\
++\end{array}$ \\
\hline Green streptococci & $\overline{-}$ & - & \pm & - \\
\hline Escherichia coli & - & $+t+$ & - & +++ \\
\hline Bacteroides fragilis & - & - & - & + \\
\hline Trichomonas vaginalis & - & + & - & - \\
\hline
\end{tabular}

* Discharge at time of examination

- to $++t=$ no growth to profuse growth on culture plates

\section{Discussion}

It seems that it is difficult to establish infection of the lower genital tract of non-human primate species with $T$ vaginalis. Indeed, recent attempts to infect the vagina of two female chimpanzees and the urethra of 
two male chimpanzees with inocula containing $5 \times 10^{5}$ actively motile $T$ vaginalis organisms failed (D Taylor-Robinson, unpublished observations). Our success in showing that squirrel monkeys are susceptible to infection of the lower genital tract with $T$ vaginalis is, therefore, of interest particularly since the model has several similarities with vaginal trichomoniasis in women. $T$ vaginalis was isolated from four of the six squirrel monkeys for periods ranging from 20 to 51 days and was accompanied usually by a vaginal discharge and by an antibody response. In common with the disease in humans the most efficient method of diagnosis was by culture rather than by examination of a wet preparation or a stained smear. ${ }^{10}$ It is noteworthy that recovery of trichomonads from animals that appeared to be infected was not achieved consistently. In one instance recovery after a "latent" phase occurred only on introduction of sterile medium into the vagina and, in two instances, after several apparently trichomonad-free animals had been caged together. The latter may be an example of a stressful situation which in some way converted a latent infection to an acute form from which trichomonads could be recovered. This would be consistent with the notion that untreated women with acute, symptomatic vaginal trichomoniasis sometimes develop a chronic asymptomatic condition from which it is very difficult to isolate $T$ vaginalis unless an environmental change-for example, hormonal -occurs which encourages parasite multiplication.

The reason why two of the squirrel monkeys $(E, F)$ could not be infected despite challenge on three occasions is unknown, but this failure does not appear to be related to vaginal $\mathrm{pH}$, glycogen content, or flora. It is, perhaps, just a reflection of the difficulty of infecting animals, as mentioned previously, and in fact is consistent with the poor results of attempts to infect women experimentally with $T$ vaginalis (see Trussell $^{1}$ ). Infections in the monkeys appeared to resolve spontaneously often after about one month. Similarly, experimental infections in women have seldom been reported to continue for long. ${ }^{1}$ For example, Hesseltine and colleagues ${ }^{9}$ were able to infect only seven of 52 women, three of whom had symptoms, and the infections apparently disappeared "within a few days".

The vaginal discharge which developed in the squirrel monkeys seemed to be a response to the trichomonads because it was not present before inoculation. It was not, however, closely correlated with recovery of $T$ vaginalis. In two monkeys (B and D) a correlation existed, but in two others (C and E) it did not. In the latter animals the discharge occurred in association with local IgG and IgA antibody responses. It could be argued that the rises in antibody titres were in response to undetected infection or to trichomonal antigen and that discharge was stimulated by these. The fifth monkey (A) had a persistent discharge which became more profuse on subsequent inoculations. It occurred irrespective of whether $T$ vaginalis was recovered but did not appear to be due to the presence of any other known bacterial pathogens. It is noteworthy that in each case the discharge contained few polymorphonuclear leucocytes and in this respect was more like the discharge associated with a Gardnerella vaginalis infection in women than with that due to $T$ vaginalis.

Each infected monkey usually developed serum IgG and local IgG and $\operatorname{IgA}$ antibody responses at some time during the series of inoculations. Rises in the titres of local antibodies were seen in four monkeys, however, even though only one of them was culture positive at the time of the response. Nevertheless, the trichomonads must have been present in sufficient numbers to stimulate a response and it is possible that the local antibodies were instrumental in eradicating the parasites or in driving them into a "latent" form. The finding that local antibody did not correlate with current infection is compatible with the observations of Street and colleagues $^{8}$ who found that local IgG and IgA antibodies to $T$ vaginalis in women correlated poorly with the ability to isolate the trichomonads.

The question of immunity based on a small number of animals is difficult to resolve. A second or third inoculation was not always successful so that some immunity may have developed. It cannot be excluded that in some instances isolation of the parasites from reinoculated monkeys occurred because of re-emergence of the organisms from a previous infection rather than because of reinfection. Nevertheless, it seems likely that reinfections did occur so that, at best, immunity to rechallenge was poor. To some extent this may have been associated with the rapid disappearance of antibody, most animals having been reinoculated when antibody had disappeared. The results suggest that naturally induced antibodies, either circulating or local, to $T$ vaginalis in women ${ }^{8}$ may not persist and thus afford little protection.

We thank Miss P A Leach for excellent technical assistance and Dr J P Ackers for helpful discussions during the course of this work. It was supported by a research student grant to DAS from the Medical Research Council.

\section{References}

1. Trussell RE. Trichomonas vaginalis and trichomoniasis. Springfield, Illinois: C C Thomas, 1947. 
2. Honigberg BM. Trichomonads of importance in human medicine. In: Kreier JP, ed. Parasitic protozoa, vol 2. New York: Academic Press, 1978;275-454.

3. Johnson G, Kupferberg AB, Hartman CG. Cyclic changes in vaginal populations of experimentally induced Trichomonas vaginalis infections in rhesus monkeys. Am J Obstet Gynecol 1950; 59:689-92.

4. Kessel JF, Gafford JA Jr. Observations on the pathology of trichomonas vaginitis and on vaginal implants with Trichomonas vaginalis and Trichomonas intestinalis. Am J Obstet Gynecol 1940; 39: 1005-14.

5. Trussell RE, McNutt SH. Animal inoculations with pure cultures of Trichomonas vaginalis and Trichomonas foetus. $J$ Infect Dis 1941;69: 18-28.
6. Diamond LS. The establishment of various trichomonads of animals and man in axenic culture. J Parasitol 1957; 43:488-90.

7. Squires S, McFadzean JA. Strain sensitivity of Trichomonas vaginalis to metronidazole. Br J Vener Dis 1962;38:218-9.

8. Street DA, Taylor-Robinson D, Ackers JP, Hanna NF, McMillan A. Evaluation of an enzyme-linked immunosorbent assay for the detection of antibody to Trichomonas vaginalis in sera and vaginal secretions. BrJ Vener Dis 1982;58:330-3.

9. Hesseltine HC, Wolters SL, Campbell A. Experimental human vaginal trichomoniasis. J Infect Dis 1942;71:127-30.

10. Spence MR, Hollander DH, Smith J, McCaig L, Sewell D, Brockman M. The clinical and laboratory diagnosis of $\mathbb{D}$ Trichomonas vaginalis infection. Sex Transm Dis 1980; 7:168-71. 